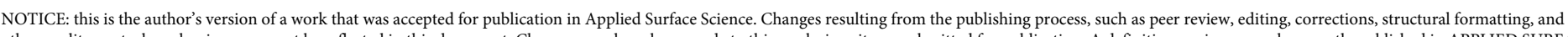

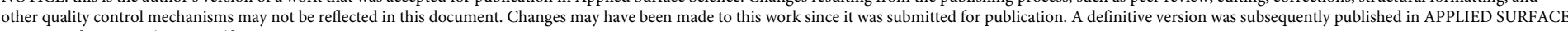
SCIENCE, [VOL336, (May 2015)] DOI: 10.1016/j.apsusc.2014.10.140

\title{
Emitter formation using laser doping technique on n- and p-type c-Si substrates
}

\author{
G. López*, P. Ortega, M. Colina, C. Voz, I. Martín, A. Morales-Vilches, A. Orpella, R. Alcubilla
}

Micro and Nanotechnologies Group, Departament d' Enginyeria Electrònica, Universitat Politècnica de Catalunya (UPC), Jordi Girona 1-3, Campus Nord, Mòdul C4, 08034 Barcelona, Spain

\section{A R T I C L E I N F O}

\section{Article history:}

Received 26 June 2014

Received in revised form

26 September 2014

Accepted 27 October 2014

Available online $\mathrm{xxx}$

\section{Keywords:}

Laser doping

PECVD

ALD

$\mathrm{Al}_{2} \mathrm{O}_{3}$

a-SiC $x$

\begin{abstract}
A B S T R A C T
In this work laser doping technique is used to create highly-doped regions defined in a point-like structure to form $\mathrm{n}+/ \mathrm{p}$ and $\mathrm{p}+/ \mathrm{n}$ junctions applying a pulsed Nd-YAG $1064 \mathrm{~nm}$ laser in the nanosecond regime. In particular, phosphorous-doped silicon carbide stacks (a-SiC $C_{x} / \mathrm{a}-\mathrm{Si}: \mathrm{H}$ (n-type)) deposited by Plasma Enhanced Chemical Vapor Deposition (PECVD) and aluminum oxide $\left(\mathrm{Al}_{2} \mathrm{O}_{3}\right)$ layers deposited by atomic layer deposition (ALD) on $2 \pm 0.5 \Omega \mathrm{cm}$ p- and n-type FZ c-Si substrates respectively are used as dopant sources.

Laser power and number of pulses per spot are explored to obtain the optimal electrical behavior of the formed junctions. To assess the quality of the $\mathrm{p}+$ and $\mathrm{n}+$ regions, the junctions are electrically contacted and characterized by means of dark $J-V$ measurements. Additionally, a diluted HF treatment previous to front metallization has been explored in order to know its impact on the junction quality. The results show that fine tuning of the energy pulse is critical while the number of pulses has minor effect. In general the different HF treatments have no impact in the diode electrical behavior except for an increase of the leakage current in $n+/ p$ junctions.

The high electrical quality of the junctions makes laser doping, using dielectric layers as dopant source, suitable for solar cell applications. Particularly, a potential open circuit voltage of $0.64 \mathrm{~V}$ ( $1 \mathrm{sun}$ ) is expected for a finished solar cell.
\end{abstract}

(c) 2014 Elsevier B.V. All rights reserved.

\section{Introduction}

Lasers are widely used for different applications in the industry of solar cells such as scribe grooves in buried contact solar cells [1], firing contacts in the laser fired contact (LFC) structure [2-4], texture surfaces [5,6], ablate dielectrics layers [7], among others. The introduction of laser processes to create doped regions into crystalline silicon (c-Si) can avoid the use of dopant diffusion in conventional high temperature furnaces that represents one of the most expensive and time-consuming processes in the fabrication line. Laser doping diffusion (LD) relies upon lasers' ability to heat locally the semiconductor surface. Doping happens during the melting 'phase' of the silicon in which dopants are incorporated (diffused) to the silicon structure [6,8]. Several methods applying laser doping technique (LD) to junction formation have been

\footnotetext{
* Corresponding author. Tel.: +349340156 71 .

E-mail address: gema.lopez@upc.edu (G. López).
}

presented to date and a wide variety of dopant source can be used in gas, liquid or solid form [9-12].

In this work we apply the LD technique to create highly-doped regions defined in a point-like structure to form $n+/ p$ and $p+/ n$ junctions and base contacts applying a pulsed Nd-YAG $1064 \mathrm{~nm}$ laser in the nanosecond regime. Dielectric layers deposited at low temperature have been used as dopant sources, particularly a phosphorous-doped silicon carbide stack (a-SiC $\mathrm{C}_{x} / \mathrm{a}-\mathrm{Si}: \mathrm{H}$ (n-type)) deposited by Plasma Enhanced Chemical Vapor Deposition(PECVD) and aluminum oxide $\left(\mathrm{Al}_{2} \mathrm{O}_{3}\right)$ layer deposited by atomic layer deposition (ALD). These layers have the advantage that, if correctly tuned, they can also work as c-Si passivating layers and reduce optical reflectance $[13,14]$. Parameters such as pulse energy and number of pulses are varied in order to find the conditions leading to the optimal electrical behavior of the formed junction. The fabricated $n+/ p$ and $p+/ n$ junctions are electrically characterized by means of dark $J-V$ measurements. We analyze how the laser parameter and the HF treatment impact on the $J-V$ curves and we calculate the series resistance as well as the $V_{\text {oc }}$ expected for 1 sun. 


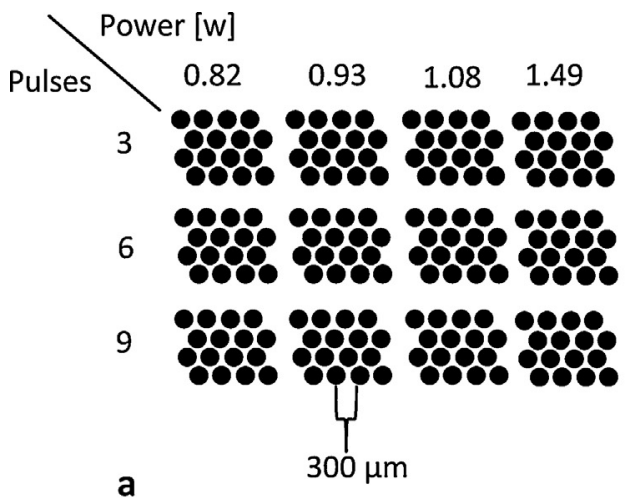

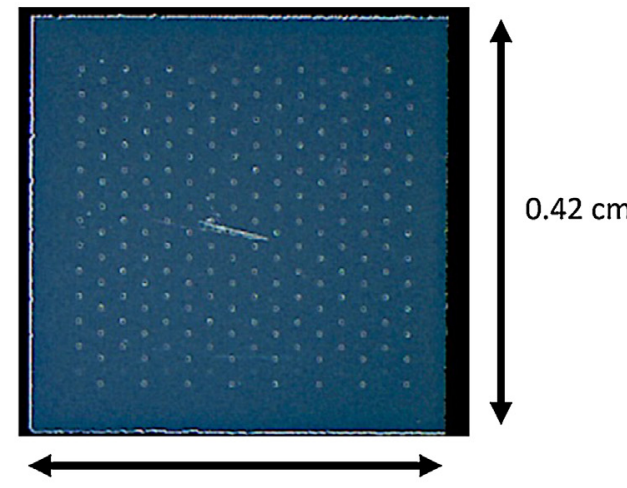

$0.42 \mathrm{~cm}$

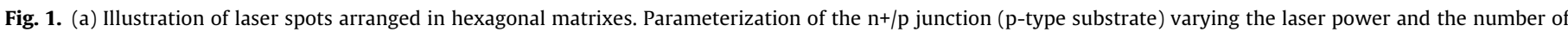
pulses. (b) Optical microscopy image of the device front side.

\section{Experimental}

\subsection{Laser system}

Laser doping was carried out using a pulsed Nd:YAG laser (StarMark SMP100 II Rofin-Baasel) working at $1064 \mathrm{~nm}$ wavelength in TEM00 mode, with a fixed frequency of $4 \mathrm{kHz}$ and a pulse duration fixed at $100 \mathrm{~ns}$. Regarding the beam characteristics, an objective lens with a focal length of $31.4 \mathrm{~cm}$ is used leading to a beam waist of $70 \mu \mathrm{m}$ radio with a Gaussian profile and a round shape. In all the experiments, the material surface to be treated was placed at the focal length. The energy of the laser beam can be adjusted by varying the intensity of the continuous lamp that pumps the $\mathrm{Nd}$ :YAG crystal. In this study, the laser pulse energy was modified by the control of lamp current from $19.4 \mathrm{~A}$ to $21 \mathrm{~A}$ and we explored the quality of the laser doped regions varying the laser power from $0.8 \mathrm{~W}$ to $1.4 \mathrm{~W}$ and the number of shots per spot: 3,6 and 9 pulses.

\subsection{Sample preparation and J-V measurements}

All the samples processed by LD were Float Zone n- and p-type crystalline silicon with a resistivity of $1.4-2.5 \Omega \mathrm{cm}, \sim 280 \mu \mathrm{m}$ thick. We started by a complete RCA cleaning sequence following the steps described by Martín et al. [4].

The p-type wafer is introduced in the PECVD chamber (direct plasma, $13.56 \mathrm{MHz}$ from ElletroRava S.P.A.) and a phosphorousdoped $\mathrm{SiC}_{x}$ stack is deposited directly on the front c-Si surface. This stack consisted of a Si-rich intrinsic $\mathrm{SiC}_{x}$ passivating film $(\sim 4 \mathrm{~nm})$, a phosphorus-doped amorphous silicon film $(\sim 15 \mathrm{~nm})$ and a stoichiometric $\mathrm{SiC}_{x}$ film $(n=2.0,75 \mathrm{~nm})$ for chemical protection purposes. Then $90 \mathrm{~nm} \mathrm{Al}_{2} \mathrm{O}_{3}$ films were symmetrically grown by thermal ALD (Savannah S200 Cambridge Nanotech) using tri-methyl aluminum $\left(\mathrm{Al}\left(\mathrm{CH}_{3}\right)_{3}\right)$ and water $\left(\mathrm{H}_{2} \mathrm{O}\right)$ vapor as film precursors. The $\mathrm{Al}_{2} \mathrm{O}_{3}$ film of the front side was removed with $\mathrm{HF}$ at $1 \%$ previous rear side protection with a photoresist film. This photoresist film was eliminated after the etching process. Finally, a $50 \mathrm{~nm}$ thick stoichiometric $\mathrm{SiC}_{x}$ film is deposited on the rear side. In fact, the studied dielectric stacks are chosen to be technologically compatible with the fabrication of interdigitated back contacted c-Si solar cells that impose strong constraints in dielectric configuration. In order to create the $n+$ regions and study laser parameters which lead to the optimal electrical behavior of the formed junction, the front surface of the samples were irradiated with the laser simultaneously enabling the diffusion of the dopant atoms and opening the dielectric layer. In this way, the processed surface is ready to be contacted. Several hexagonal matrixes of spots separated a distance (pitch) of $300 \mu \mathrm{m}$ (Fig. 1) were done. Each matrix corresponds to one device with a total area of $0.42 \mathrm{~cm} \times 0.42 \mathrm{~cm}$ and the laser conditions (power and number of pulses) were fixed within the same array and varied between them.

Base contacts ( $\mathrm{p}+$ regions) are defined with $600 \mu \mathrm{m}$ pitch at the rear surface before an e-beam evaporation of $\mathrm{Ti} / \mathrm{Al}$ of both sides. No HF treatment previous metallization was done unless otherwise stated. Finally an annealing in $\mathrm{N}_{2} / \mathrm{H}_{2}$ at $375^{\circ} \mathrm{C}$ for 10 min was carried out in order to increase the negative fixed charge density located at the $\mathrm{Al}_{2} \mathrm{O}_{3} / \mathrm{c}$-Si interface that favors the passivation quality and improves the metal-silicon contacts.

The same structure is defined for $n$-type substrates where $p+/ n$ junctions are defined. The only difference is the position of the dielectric films as it can be seen in Fig. 2, i.e. $\mathrm{Al}_{2} \mathrm{O}_{3} / \mathrm{SiC}_{x}$ layer is on top of the device while $\mathrm{SiC}_{x}$ n-type stack is at the back.

Dark $J-V$ measurements were done at $25^{\circ} \mathrm{C}$ and the current density is calculated dividing the measured current by the device area.

\section{Results and discussion}

The advantages of using $\mathrm{Al}_{2} \mathrm{O}_{3}$ and a-SiC $/$ a-Si:H (n-type) dielectric layers as dopant sources is that correctly tuned they can also be used as passivating layers. The surface passivation quality was determined by means of lifetime measurements (Sinton WCT-120). All the samples processed on p- and n-type substrates exhibited a high initial lifetime before the laser processing over $1 \mathrm{~ms}$ at $1 \mathrm{sun}$ (Fig. 3) corresponding to surface recombination velocities lower than $10 \mathrm{~cm} / \mathrm{s}$.

\subsection{DarkJ-V measurements}

Fig. 4 shows $J-V$ characteristics for $\mathrm{p}+/ \mathrm{n}$ and $\mathrm{n}+/ \mathrm{p}$ junctions created by laser doping. The comparison between devices irradiated with different laser powers show a rectifying behavior in all the diodes with a clear exponential trend at mid-injection with the exception of the diodes created with the highest power $(1.49 \mathrm{~W})$. This latter behavior could be due to an excessive melting during a too strong laser doping process that would cause surface and lattice damage. If the pulse energy is too high, the surface starts being ablated and can introduce damage to the silicon [15].

Fig. 5 shows optical profilometry data for three different laser powers, i.e. $0.93,1.08$ and $1.49 \mathrm{~W}$. The highest laser power leads 

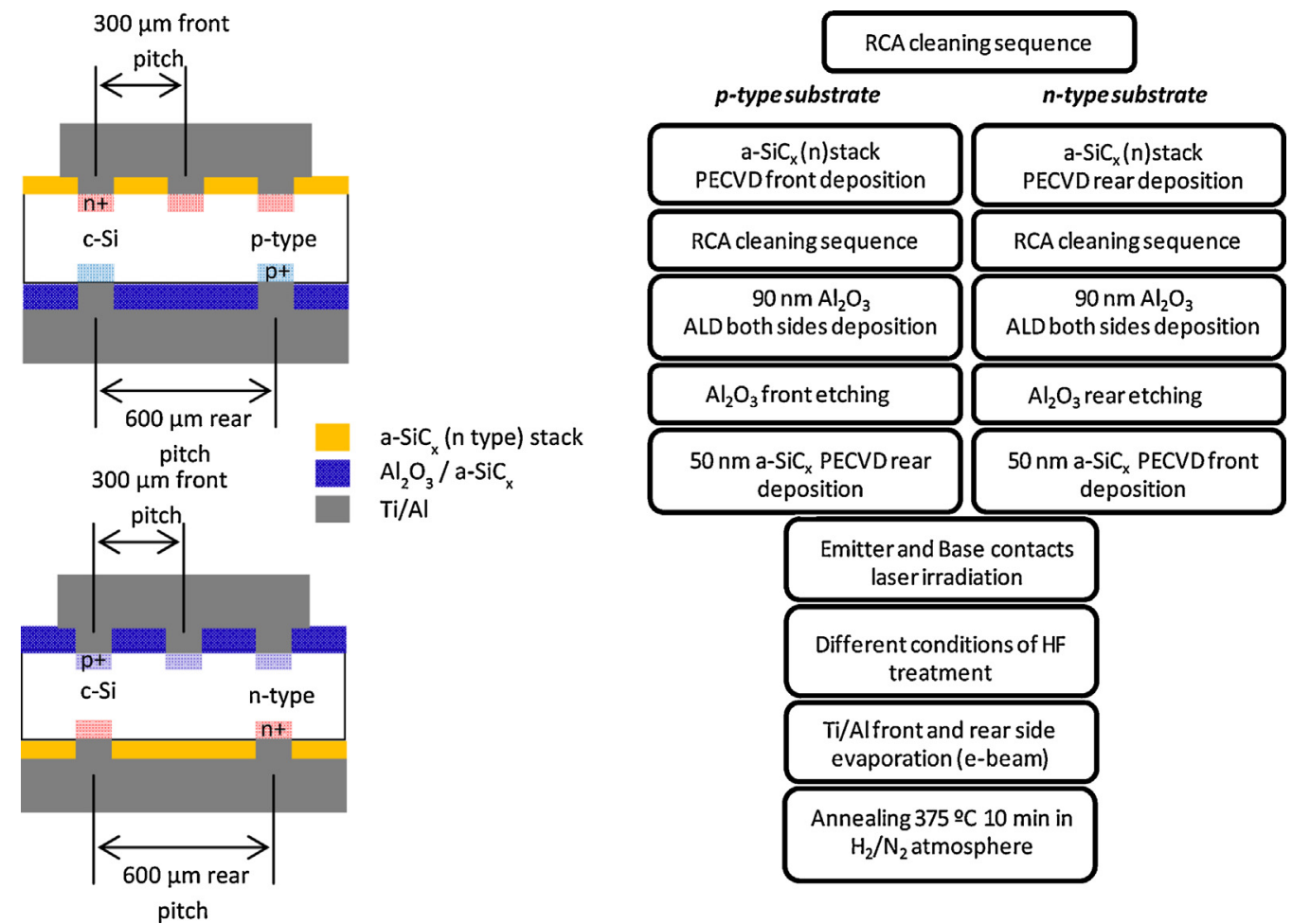

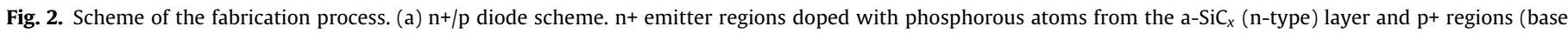
contacts) from $\mathrm{Al}_{2} \mathrm{O}_{3}$ layer. (b) $\mathrm{p}+/ \mathrm{n}$ diode scheme. $\mathrm{p}+$ emitter regions doped with aluminum atoms from $\mathrm{Al}_{2} \mathrm{O}_{3}$ layer and $\mathrm{n}+$ regions (base contacts) from a-SiC ${ }_{x}$ ( $\mathrm{n}$-type).

to a penetration depth on the order of 3 micrometer, causing damage in the silicon structure and a possible removal of the dopant $[16,17]$. Additionally, we can see that the radius of the affected region increases with laser power, ranging from $30 \mu \mathrm{m}$ to $45 \mu \mathrm{m}$.

Regarding the $J-V$ characteristics we can observe that the quality of the diodes are very similar indicating a laser parameter window from $0.8 \mathrm{~W}$ to $1.0 \mathrm{~W}$ and 3,6 and 9 pulses available to create both $\mathrm{p}+$ and $\mathrm{n}+$ regions. However, the optimum behavior is done for $0.9 \mathrm{~W}$ and $1 \mathrm{~W}, 6 / 9$ pulses for $\mathrm{p}+/ \mathrm{n}$ junction and $0.9 \mathrm{~W}, 3 / 6$ pulses and $0.8 \mathrm{~W} / 9$ pulses for $\mathrm{n}+/ \mathrm{p}$ junction. Major differences in leakage

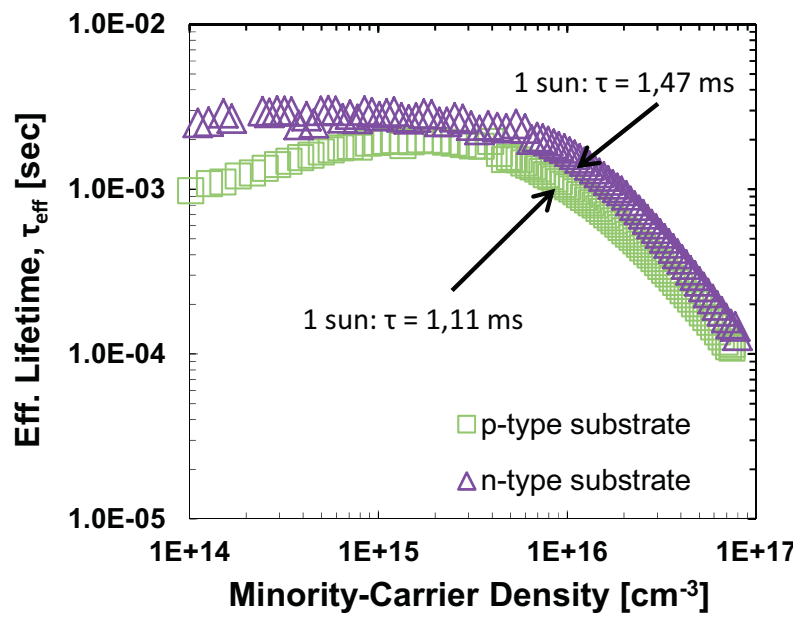

Fig. 3. Effective lifetime vs. excess carrier density for $\mathrm{p}$ and n-type c-Si samples. p-Type sample with a-SiC ${ }_{x}$ (n-type) stack and a-SiC $C_{x}$ capping layer in the front side and $90 \mathrm{~nm} \mathrm{Al} \mathrm{O}_{3}$ and a-SiC ${ }_{x}$ capping layer in the back side. n-Type sample is front side covered by $90 \mathrm{~nm} \mathrm{Al} \mathrm{O}_{3}$ and a-SiC $\mathrm{C}_{x}$ capping layer and $\mathrm{a}-\mathrm{SiC}_{x}$ in the back side. current are found as the laser power increase for the case of $n+/ p$ junction (clearly visible in the reverse bias region), while in the case of $\mathrm{p}+/ \mathrm{n}$ remains at the same level. On the other hand, highest energy condition originates a Schottky diode behavior, probably due to direct contact between metal over a low or non-doped semiconductor region.

\subsection{HF surface treatment}

Additional experiments have been carried out in order to know if a treatment of diluted HF before the metallization step impacts on the electrical behavior of the diodes. This treatment is usually done for removing the native $\mathrm{SiO}_{2}$ from the $\mathrm{Si}$ surface and to ensure a metal-semiconductor ohmic contact. Fig. 6 shows the results for the $0.9 \mathrm{~W}$ and 6 pulses case. No HF treatment, 20 seg and $35 \mathrm{seg}$ in $\mathrm{HF} 1 \%$ was done for both $\mathrm{p}$ and n-type substrate. As we can see the HF treatment has no impact in the electrical characteristics for $\mathrm{p}+/ \mathrm{n}$ junction. However, and increase in the leakage current is observed for $n+/ p$ junction when a HF treatment is done. In our opinion, this behavior is related to pinholes in the a-SiC $C_{x}$ (n-type) films where the native oxide is removed by the HF treatment and the subsequent metallization results in shunting paths. Notice that more than $90 \%$ of device area consists of a metal layer over an insulator film and any absence of it allows the metal to directly contact the c-Si substrate. This effect is strongly reduced for the $\mathrm{Al}_{2} \mathrm{O}_{3} / \mathrm{a}-$ $\mathrm{SiC}_{X}$ stack since the $\mathrm{Al}_{2} \mathrm{O}_{3}$ layer is deposited by ALD technique that lead to a much less defect density in the films compared to PECVD one.

In all cases the dark $J-V$ curves flatten at high voltage mainly due to ohmic losses hindering the characterization of the exponential current mechanism. In order to evaluate the quality of this exponential trend, we have measured the best $\mathrm{p}+/ \mathrm{n}$ and $\mathrm{n}+/ \mathrm{p}$ diode at different temperatures in the $298-363 \mathrm{~K}$ range. $J-V$ curves were 


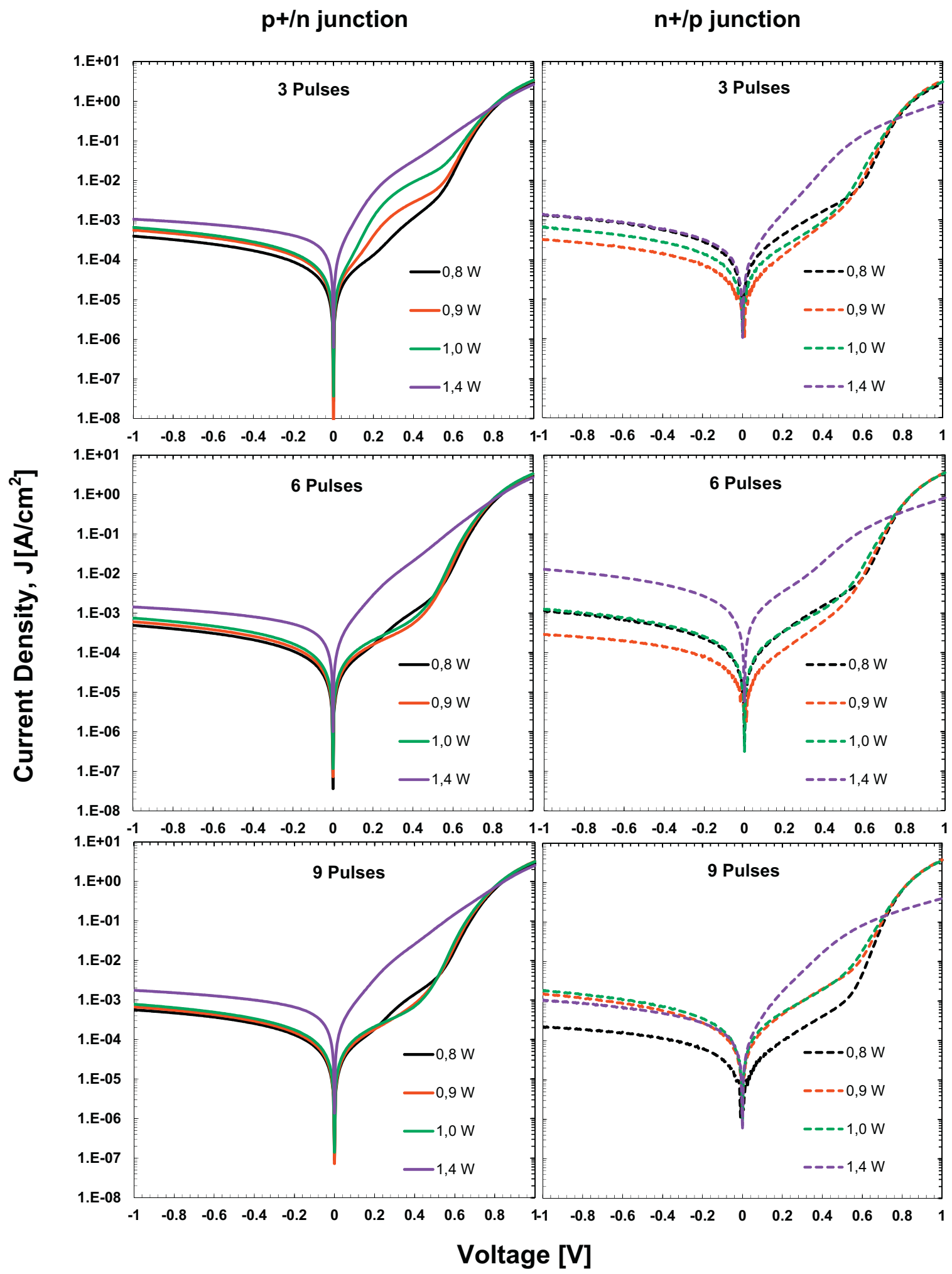

Fig. 4. Dark $J-V$ characteristics of $\mathrm{p}+/ \mathrm{n}$ and $\mathrm{n}+/ \mathrm{p}$ created from $\mathrm{Al}_{2} \mathrm{O}_{3} / \mathrm{SiC}_{x}$ (left) and stack a-SiC $C_{x}$ (n type) (right) respectively for different laser powers. From top to bottom different pulses are evaluated.

fitted using the following two diode expression and taking into account that $R_{\mathrm{s}}$ parameter does not vary with temperature:

$J(V)=J_{01}\left(e^{A\left(V-J(V) R_{S}\right.}-1\right)+J_{02}\left(e^{A\left(V-J(V) R_{S}\right.}-1\right)+\frac{V-J(V) R_{S}}{R_{\text {shunt }}}$ where for every exponential trend $J_{0}$ is the saturation current density, $A(A=q / n K T)$ is an exponential factor and $n$ is the ideality factor respectively. From the dependence of $A$ and the corresponding $J_{0}$ on the temperature, the carrier transport mechanism behind the exponential trend can be identified. A summary of the basic 


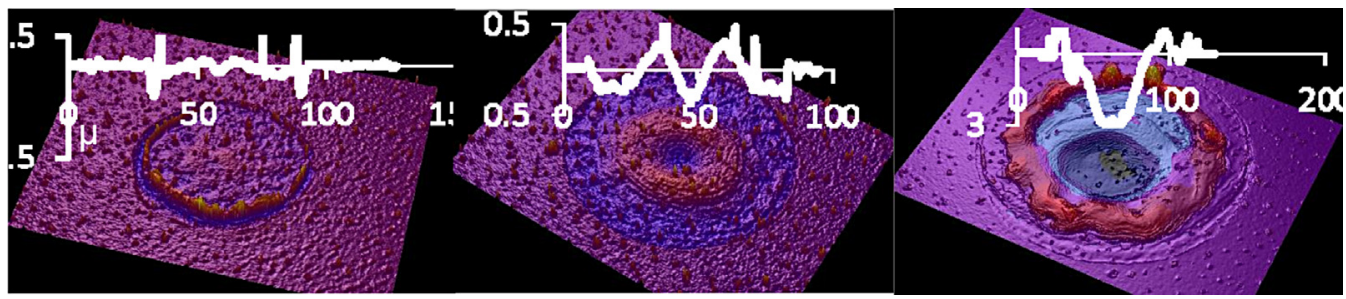

Fig. 5. White light interferometric images for three different laser powers, i.e. $0.93,1.08$ and 1.49 W. Inset curves of profilometer measurements are also shown.

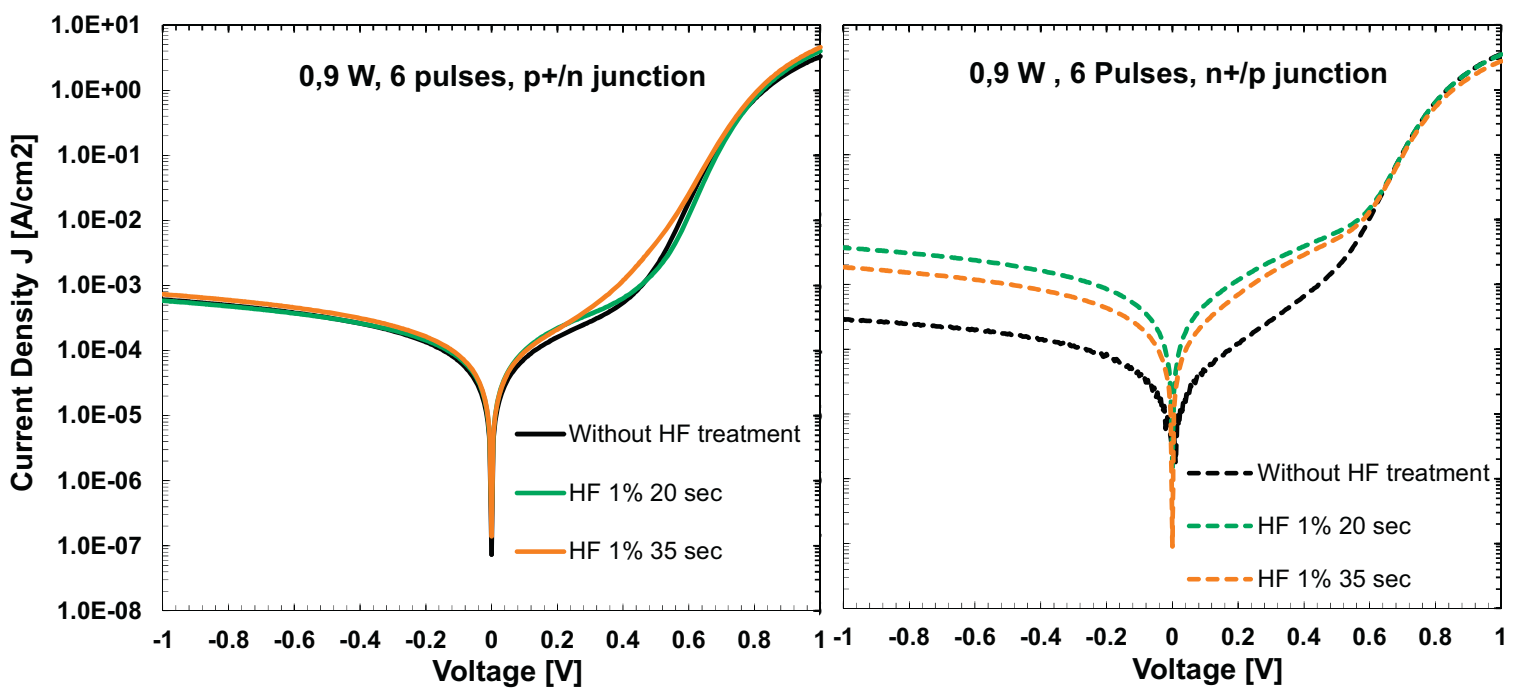

Fig. 6. Dark $J-V$ characteristics of $\mathrm{p}+/ \mathrm{n}$ and $\mathrm{n}+/ \mathrm{p}$ created for $0.9 \mathrm{~W}$ and 6 pulses. No HF treatment, HF $1 \%$ for $20 \mathrm{~s}$ and $35 \mathrm{~s}$ done before metallization process.

conduction mechanisms is given in Table 1. Applying this electrical model and assuming an ideality factor of one for the main current mechanism related to the first exponential dependence in Eq. (1) $(n=1), J_{01}$ can be extracted at different temperatures. All these data can be arranged in an Arrhenius plot where the logarithm of $J_{01}$ is plotted against the inverse of the temperature. In this type of plots, a straight line is expected for current mechanism thermally activated and their activation energy can be extracted from the line slope. As it is shown in Fig. 7 the Arrehnius plot reveals an activation energy of $1.1 \mathrm{eV}$ corresponding to the silicon bandgap. This result together with the ideality factor of 1 indicates that current is controlled by minority carrier recombination at the quasi-neutral c-Si bulk. Additionally, we can conclude that recombination at the space charge region and thus crystal damage is not dominant in the device performance.

Due to the high quality of the laser doped regions and the surface passivation provided by dielectric films, this technique is well suited to c-Si solar cells. Fig 8 shows dark $J-V$ measurements and the resulting theoretical curves once the influence $R_{\mathrm{S}}$

Table 1

Basic transport mechanisms. $E_{\mathrm{g}}$ is the energy gap, $K$ is the Boltzmann constant, $T$ is the absolute temperature, $n$ the ideality factor, $E_{\mathrm{ac}}$ is the activation energy, and $\varphi_{\mathrm{B}}$ is the barrier energy.

\begin{tabular}{llll}
\hline Transport mechanisms & $J_{0}$ & $A$ & $n$ \\
\hline Diffusion & $J_{0} \propto \exp \left(-E_{\mathrm{g}} / K T\right)$ & $q / K T$ & $n=1$ \\
Recombination & $J_{0} \propto \exp \left(-E_{\mathrm{g}} / 2 K T\right)$ & $q / n K T$ & $1<n \leq 2$ \\
Tunneling & $J_{0} \propto \exp \left(-E_{\mathrm{ac}} / K T\right)$ & const. & $n \neq$ const. \\
Thermionic & $J_{0} \propto\left[\exp \left(-\varphi_{\mathrm{B}} / K T\right)\right] K T^{3 / 2}$ & $q / K T$ & $n=1$ \\
\hline
\end{tabular}

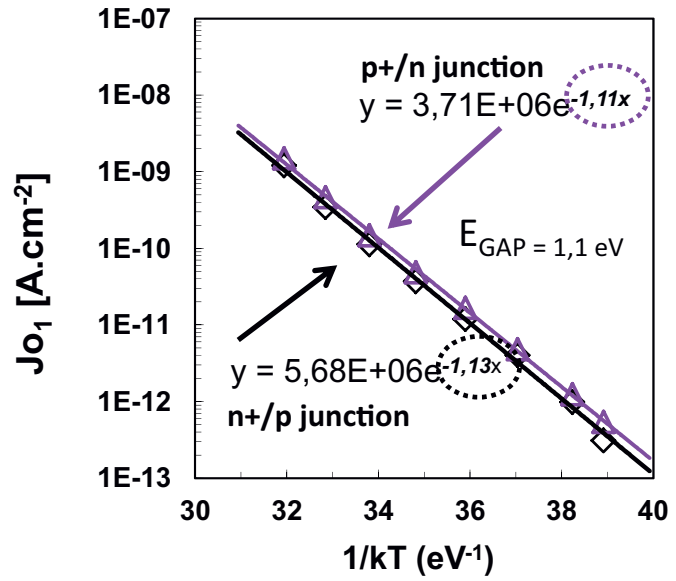

Fig. 7. Arrehnius plot of the $J_{01}$ against $1 / K T$. Dark $J-V$ measurements at different temperatures were done for $\mathrm{p}^{+} / \mathrm{n}$ and $\mathrm{n}+/ \mathrm{p}$ junction formed at $0.9 \mathrm{~W}, 6$ pulses and without HF treatment. The exponential gives activation energy of $1.1 \mathrm{eV}$ corresponding to the silicon $E_{\text {gap }}$

has been canceled in order to a correct estimation of $V_{\mathrm{oc}}$ from the dark $J-V$ curve (the normalized series resistance considering the diode area is $0.15 \Omega \mathrm{cm}^{2}$ in both cases). As it can be observed, assuming a photogenerated current density of $36 \mathrm{~mA} / \mathrm{cm}^{2}$ at 1 sunillumination, $\mathrm{a} V_{\mathrm{oc}}$ about $0.63 \mathrm{~V}$ and $0.64 \mathrm{~V}$ are expected for $\mathrm{p}+/ \mathrm{n}$ and $\mathrm{n}+/ \mathrm{p}$ junctions respectively. These values are promising results and can be considered in the state of the art of commercial c-Si solar cells. 


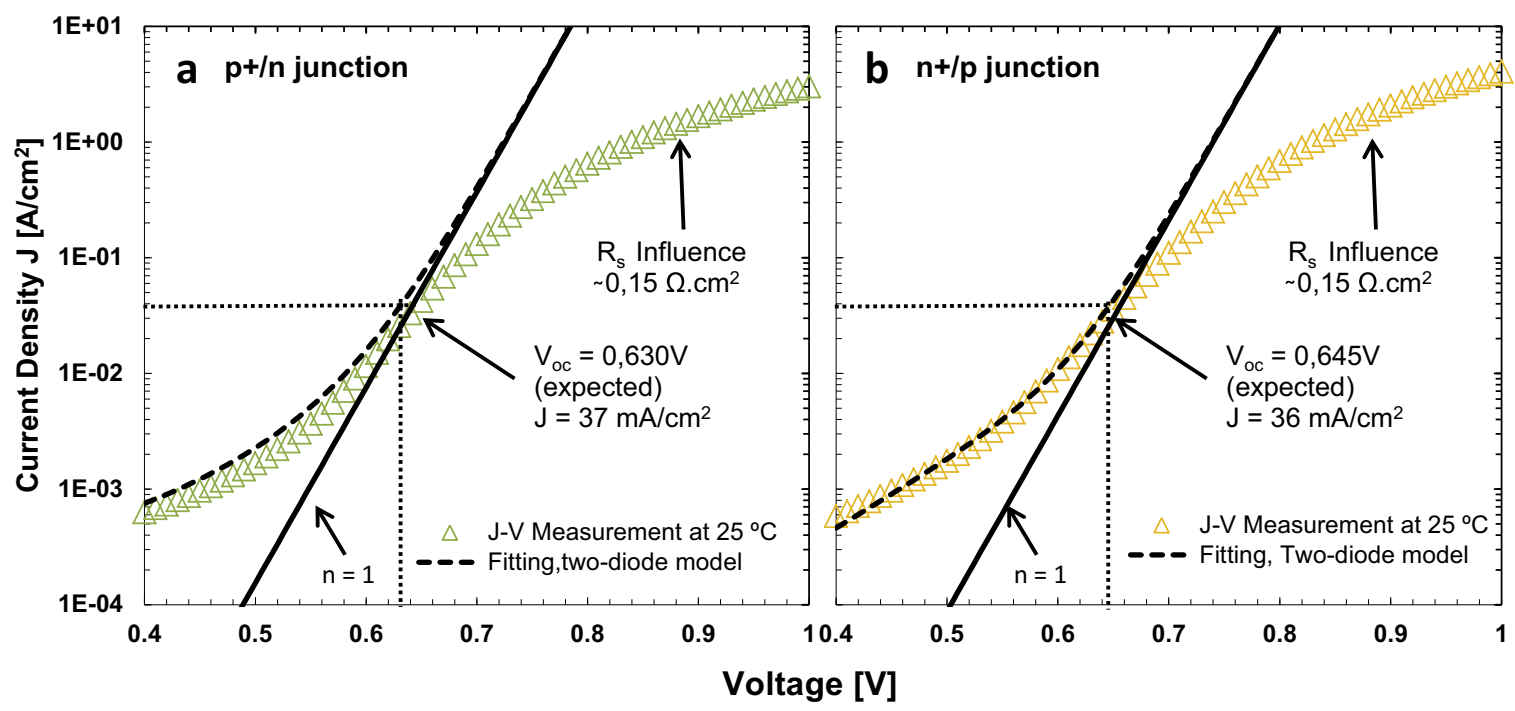

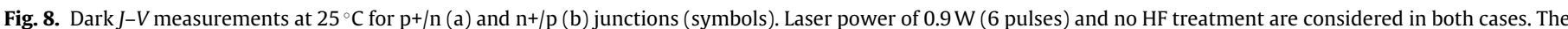

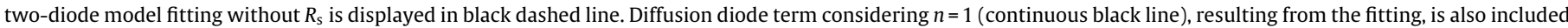
as a reference.

\section{Conclusions}

In this work we have explored different laser conditions, i.e. laser power and number of laser pulses, to create reliable $p+/ n$ and $\mathrm{n}+/ \mathrm{p}$ junctions on $\mathrm{c}-\mathrm{Si}$ using Laser doping technique. In this case, dielectric layers $\left(\mathrm{Al}_{2} \mathrm{O}_{3}\right.$ and a- $\mathrm{SiC}_{X}$ (n doped)) were applied as both dopant sources and surface passivation layers. Optimal laser conditions were established studying systematically dark $J-V$ measurements. Excellent quality of the $\mathrm{p}^{+}$and $\mathrm{n}+$ regions has been formed from $0.8 \mathrm{~W}$ to $1 \mathrm{~W}$ and $3 / 6 / 9$ pulses. Additionally, a study of a diluted HF treatment before the metallization process has been also done concluding that best electrical behavior corresponds to no HF treatment. Finally, dark $J-V$ measurements for different temperatures have demonstrated that the main current mechanism is linked to minority carrier recombination in the quasi-neutral bulk and, thus, that laser damage is not dominant in device performance. The high quality of the junctions and the excellent surface passivation makes laser doping technique using dielectric layers as dopant source suitable for solar cells applications. An open circuit voltage at 1 sun-illumination of about $640 \mathrm{mV}$ is expected for this type of solar cells.

\section{Acknowledgements}

This work has been supported by the Spanish Government under project TEC 2011-26329 and by the European Union's Seventh Framework Programme for research, technological development and demonstration under project HERCULES (Grant agreement: 608498).

\section{References}

[1] A.W.Y. Ho, S.R. Wenham, Buried contact solar cells with innovative rear localised contacts, Prog. Photovolt. Res. Appl. 12 (2004) 297-308.

[2] E. Schneiderlöchner, R. Preu, R. Lüdemann, S.W. Glunz, Laser-fired rear contacts for crystalline silicon solar cells, Prog. Photovolt. Res. Appl. 10 (2002) 29-34.
[3] D. Carrio, P. Ortega, I. Martín, G. López, J.M. López-González, A. Orpella, C. Voz, R. Alcubilla, Rear contact pattern optimization on 3D simulations for IBC solar cells with point-like doped contacts, in: 4th Int. Conf. Silicon Photovolt., 2014.

[4] I. Martín, P. Ortega, M. Colina, A. Orpella, G. López, R. Alcubilla, Laser processing of $\mathrm{Al}_{2} \mathrm{O}_{3} / \mathrm{a}-\mathrm{SiC} \mathrm{C}_{x}: \mathrm{H}$ stacks: a feasible solution for the rear surface of high-efficiency p-type c-Si solar cells, Prog. Photovolt. Res. Appl. 21 (2012) $1171-1175$.

[5] L. Pirozzi, U.B. Vetrella, M. Falconieri, E. Salza, A laser system for silicon solar cell processing: design, setup and operation, Mater. Sci. Forum 173-174 (1995) 319-324.

[6] L. Pirozzi, U. Besi-Vetrella, E. Salza, Innovative applications of laser technology in photovoltaics, in: Proc. SPIE Conf. Laser Appl. Microelectron. Optoelectron. Manuf. II, 1997.

[7] A. Knorz, M. Peters, A. Grohe, C. Harmel, R. Preu, Selective laser ablation of SiN layers on textured surfaces for low temperature front side metallizations, Prog. Photovolt. Res. Appl. 17 (2009) 127-136.

[8] A. Ogane, K. Hirata, K. Horiuchi, A. Kitiyanan, Y. Uraoka, T. Fuyuki, Feasible control of laser doping profiles in silicon solar cell processing using multiple excitation wavelengths, in: 33rd IEEE Photovolt. Spec. Conf., 2008.

[9] G.B. Turner, D. Tarrant, G. Pollock, R. Pressley, R. Press, Solar cells made by laser-induced diffusion directly from phosphine gas, Appl. Phys. Lett. 39 (1981) 967-969.

[10] D. Kray, A. Fell, S. Hopman, K. Mayer, G. Willeke, S.W. Glunz, Laser chemica processing (LCP). A versatile tool for microstructuring applications, Appl. Phys. A: Mater. Sci. Process. 93 (2008) 99-103.

[11] E. Fogarassy, R. Stuck, J.J. Grob, P. Siffert, Silicon solar cells realized by laser induced diffusion of vacuum-deposited dopants, J. Appl. Phys. 52 (1981) 1076-1082.

[12] M. Colina, I. Martín, C. Voz, A. Morales-Vilches, P. Ortega, G. López, A. Orpella R. Alcubilla, I. Sánchez-Aniorte, C. Molpeceres, Optimization of laser doping processes for the creation of $\mathrm{p}+$ regions from solid dopand sources, in: 27 th EUPVSEC, 2012, pp. 1885-1889.

[13] G. López, P. Ortega, C. Voz, I. Martín, M. Colina, A. Morales-Vilches, A. Orpella, R. Alcubilla, Surface passivation and optical characterization of $\mathrm{Al}_{2} \mathrm{O}_{3} / \mathrm{a}-\mathrm{SiC}_{x}$ stacks on c-Si substrates, Beilstein J. Nanotechnol. 4 (2013) 726-731.

[14] I. Martín, M. Colina, A. Coll, G. López, P. Ortega, A. Orpella, R. Alcubilla, c-Si solar cells based on laser-processed dielectric films, in: 4th Int. Conf. Silicon Photovolt., 2014.

[15] M. Okanovic, U. Jäger, M. Ahrens, U. Stute, A. Grohe, R. Preu, Influence of different laser parameters in laser doping from phosphosilicate glass, in: 24th EUPVSEC, 2009, pp. 24-27.

[16] A. Fell, E. Franklin, D. Walter, D. Suh, K.J. Weber, Laser doping from $\mathrm{Al}_{2} \mathrm{O}_{3}$ layers, in: 27th EUPVSEC, 2012, pp. 706-708.

[17] Z. Hameiri, L. Mai, T. Puzzer, S.R. Wenham, Influence of laser power on the properties of laser doped solar cells, Sol. Energy Mater. Sol. Cells 95 (2011) 1085-1094. 